\title{
An analysis of Total Gaseous Mercury (TGM) concentrations across the UK from a rural sampling network
}

\section{Abstract}

Total gaseous mercury was collected at ten sites which comprise part of the UK rural heavy metals monitoring network, between 2005 and 2008. Using the gold amalgam technique to capture total gaseous mercury, samples were analysed using a Tekran 2537A mercury vapour analyser. The data showed no upward or downward trend in atmospheric mercury concentrations over the period, with 4-year average concentrations between $1.3-1.9 \mathrm{ng} \mathrm{m}^{-3}$, which are in line with other studies' observed northern hemispheric background concentrations of between $1.5-1.7 \mathrm{ng}$ $\mathrm{m}^{-3}$. Using data from nine of the sites, we were able to show seasonality within the data and through kriging we were able to interpolate the TGM concentrations over the UK, revealing a south-east to north-west declining concentration gradient. Using continuous speciated mercury measurements from one of the network sites, we show through wind sector analysis and air-mass back trajectories that this spatial trend is likely to be due to air masses moving over the UK from continental Europe on easterly winds. The levels of TGM recorded in the south-east of the UK also more closely match observed background TGM levels on the continent, which could indicate that the TGM concentrations from the north of the UK are a better reflection of the true North Atlantic atmospheric mercury background level.

\section{Introduction}


Mercury is emitted to the atmosphere from both natural and anthropogenic sources as well as through re-emission of previously deposited mercury. Natural emission sources include geothermal systems, volcanoes and the sea ${ }^{1-3}$. However, most of the mercury present in our atmosphere is the result of anthropogenic emissions, from sources such as burning coal, incineration of waste and chemical processing such as the Chlor-Alkali process. Anthropogenic emissions are thought to comprise up to two-thirds of all mercury emitted to the atmosphere ${ }^{3-5}$.

The most prevalent form of mercury in the atmosphere is that of its elemental state, existing as $\mathrm{Hg}^{0}$, mercury gas. This makes up $>95 \%$ of total atmospheric mercury ${ }^{3}$. In this form it is largely unreactive with low wet and dry deposition rates, meaning it has a long residence time in the order of 1 year, giving it a large part in the global cycling of mercury ${ }^{6-7}$. The remainder of atmospheric mercury is made up of reactive gaseous (RGM) and particulate mercury $\left(\mathrm{Hg}^{\mathrm{P}}\right)$. This is $\mathrm{Hg}^{2+}$ either as part of organic or inorganic molecules, free in the atmosphere (in the case of RGM) ${ }^{7}$, or adsorbed onto other particles (in the case of $\left.\mathrm{Hg}^{\mathrm{P}}\right)^{8-10}$. They can be formed from oxidation of $\mathrm{Hg}^{0}$ in the atmosphere ${ }^{8-10}$, or more likely are emitted directly from anthropogenic or volcanic point sources. RGM has significant importance for atmospheric mercury at the poles, where during polar sunrise, large atmospheric mercury depletion events (AMDEs) occur ${ }^{11}$ due to rapid photochemical oxidation of $\mathrm{Hg}^{0}$ by halogen radicals to form quickly deposited RGM ${ }^{12}$ and ozone ${ }^{9,13}$. Both of these species have a low residence time in the atmosphere, being easily removed by wet and dry deposition processes ${ }^{14}$, therefore directly emitted species have a limited range beyond their sources. 
Atmospheric mercury levels increased dramatically during the industrial revolution, peaking in the mid $1980 \mathrm{~s}^{15}$. Since the early 1990 s the fate of atmospheric mercury has become a more prominent interest, mainly due to its toxic effects on humans, wildlife and whole ecosystems. Since the incident in Minamata Bay, Japan during the 1950 s and 1960 s, specific concern has been given to the bioaccumulation of methyl mercury, one of mercury's most toxic forms, especially through the consumption of fish ${ }^{7,16-18}$. This concern is highlighted by the number of fish consumption guidelines issued by several industrialised countries and in a recent paper concerned about the effect of low-level environmental mercury on human health ${ }^{19}$.

Through the United Nations Economic Commission for Europe (UNECE) convention on Long-Range Trans-boundary Air Pollution (LRTAP) ${ }^{7}$, the European Air Quality $4^{\text {th }}$ Daughter Framework Directive requires the monitoring of atmospheric mercury, and this has also formed part of the European Monitoring and Evaluation Programme (EMEP). It is under this requirement that the UK Department for the Environment, Food and Rural Affairs (DEFRA) and the UK's devolved administrations (the Scottish Government, National Assembly for Wales and the Department for the Environment in Northern Ireland) support a network of rural heavy metal monitoring sites across the UK including two fixed continuous atmospheric mercury monitoring sites. The network and one of the continuous monitoring sites are currently operated by the Centre for Ecology \& Hydrology (CEH).

Here for the first time, the total gaseous mercury (TGM) in air data for the rural network from 2005 to 2008 are presented and an analysis of the results is made, including an interpolation of the averaged data over the UK. This paper will 
also discuss events in the long-term continuous speciated background mercury monitoring dataset collected at Auchencorth Moss, a rural monitoring site in southern Scotland.

\section{Measurement method and Measurement sites}

\section{TGM Network}

Measurements of TGM, which we define as comprising all three mercury species $\left(\mathrm{Hg}^{0}, \mathrm{RGM}\right.$ and $\mathrm{Hg}^{\mathrm{P}}$ ), were made at 10 sites across the UK (Table 1, Figure 2) using integrated samplers based on the gold-amalgamation technique. These automatic samplers use a small pump to pull air through two sequential gold traps (122 mm x $4 \mathrm{~mm}$ inner diameter quartz glass tube packed with $\sim 0.37 \mathrm{~g}$ gold coated sand and quartz wool plugs) at approximately $20 \mathrm{ml} \mathrm{min}^{-1}$. The mercury in the sampled air forms an amalgam with the gold, which is subsequently released by thermal desorption during analysis. Two gold traps are used in sequence, the first to capture the bulk of the mercury with the second to catch any mercury that breaks through the first. During sampling both cartridges are heated to $100{ }^{\circ} \mathrm{C}$ using an internal heater, to minimise the potential for the gold surface to become coated with water vapour or organic compounds which would impede mercury uptake. A dry gas meter is used to measure the total volume of air sampled, to give a quantitative concentration for mercury in the air as mass per unit volume (Figure 1). In practice, uptake of $\mathrm{Hg}^{\mathrm{P}}$ by the sampler may be poor because of the low sampling rate; this is unlikely to cause a major bias in the overall results because of the small fraction $(<5 \%)$ of $\mathrm{TGM}^{3}$ that is contributed by $\mathrm{Hg}^{\mathrm{P}}$ 


\section{Sampler - V.1}
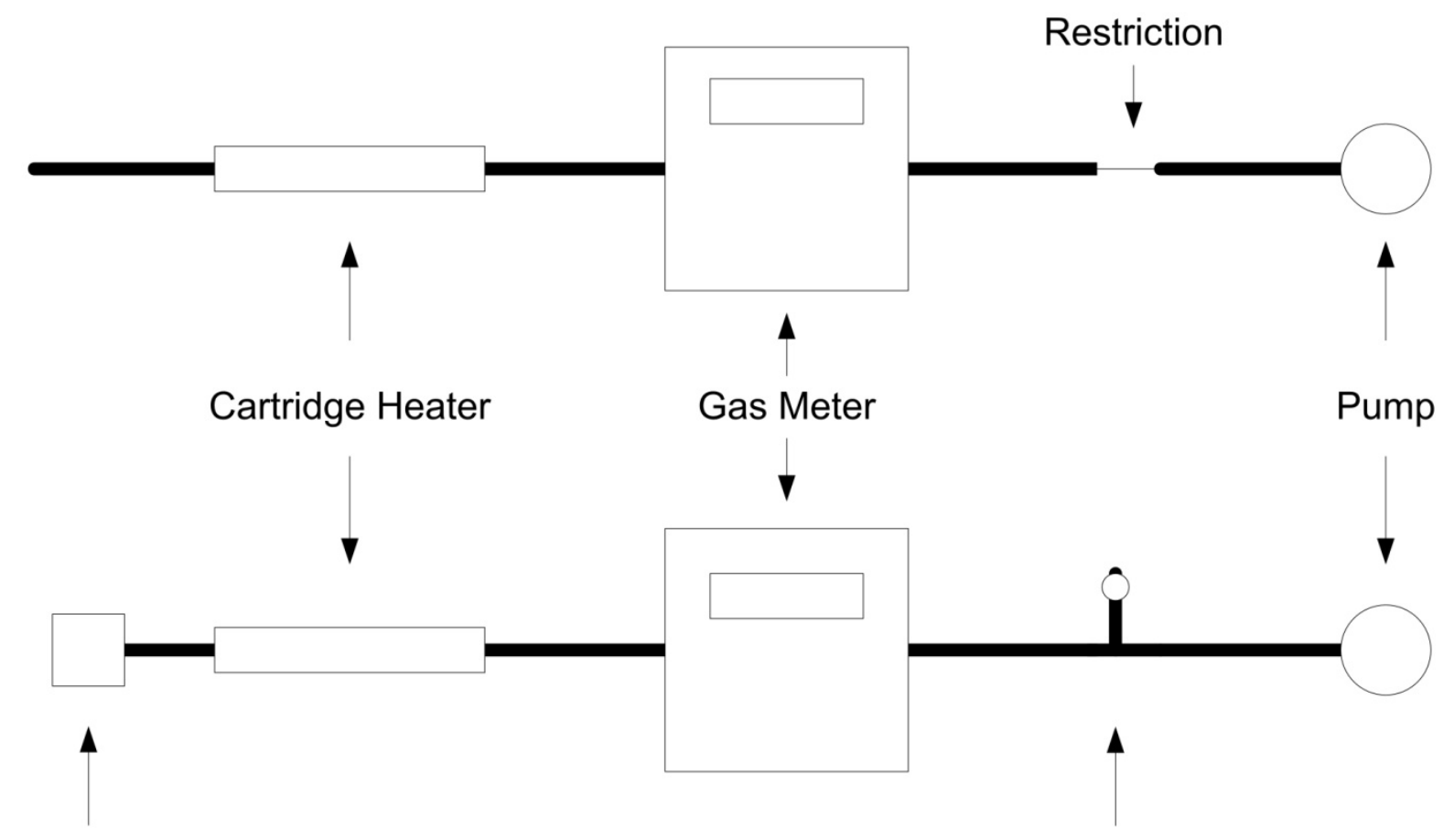

Gas Meter

Pump

Inlet Filter

Needle Valve

\section{Sampler - V.2}

Fig. 1 TGM network sampler schematic, showing the design of the earlier samplers (V.1) and the later version (V.2). See text for details.

The traps were changed on an approximate 2-weekly basis by a local site operator, who, taking care not to contaminate them, sealed them and returned them to the CEH laboratory for analysis. Analysis was performed using a custom built interface for a Tekran 2537A mercury analyser. After calibration of the 2537A using its internal permeation source, the two traps were individually thermally desorbed for two 30 -second periods in a flow of argon $\left(30 \mathrm{ml} \mathrm{min}^{-1}\right)$ and the mercury present captured by the internal gold traps of the 2537A. The internal traps were then 
thermally desorbed and analysed using cold vapour atomic fluorescence spectroscopy (CVAFS) $(\lambda=253.7 \mathrm{~nm})^{20-21}$.

At several intervals during the sampling period, sample trap sets were sent out to one site as field blanks, being treated in exactly the same way as exposed traps, but without having sampled any air. These field blank traps were then analysed for mercury. As each field blank was analysed, the average blank value was updated and used to adjust subsequent sample trap analysis results. The average field blank values for the sequential traps were $0.006 \pm 0.003 \mathrm{ng}$ and 0.012 $\pm 0.011 \mathrm{ng}$ for the first and second traps respectively. These are small relative to the typical amounts of mercury trapped during a 2-week sampling period, of $0.6 \mathrm{ng}$.

The resulting values for mercury contents on the two sequential traps were then combined and the measured sample volume was used to calculate the average concentration of TGM in the air over the sampling period. Before the traps were reused, they were heated in zero air $\left(20 \% \mathrm{O}_{2}, 80 \% \mathrm{~N}_{2}\right)$ to ensure they were free from residual contaminants.

Before being dispatched to the field the individual gas meters were calibrated and recorded sample volumes were adjusted accordingly. During the summer of 2007 the samplers underwent a redesign to make them more resilient to changing weather conditions. Changes made were the incorporation of a $0.2 \mu \mathrm{m}$ Teflon prefilter to prevent debris and insects becoming trapped in the gold traps, the flow control method was altered from an in-line restriction to a controllable air bypass, and the cartridge insertion method was changed. These changes, however, led to sampling problems related to large changes in the apparent sample flow rate, creating large sample volumes, but low recorded TGM levels. This can be seen from the two-week sample volume mean and standard deviations: For the old sampler 
setup this was $0.45 \pm 0.18 \mathrm{~m}^{3}$ and for the new setup it was $0.95 \pm 0.87 \mathrm{~m}^{3}$. The original design therefore was the more reliable and consistent sampling setup.

Whilst it is probably reasonable to assume that the introduction of the pre-filter may have adversely impacted the capture of $\mathrm{RGM}$ and $\mathrm{Hg}^{\mathrm{P}}$ leading to a small decline in detected mercury levels, the difference in values between accepted data before the sampler modification and the erroneous data thereafter was in some cases a reduction of up to $80 \%$, indicating that this was not the main cause, which is most likely an engineering problem caused by restrictions to flow and sub-ambient pressures in the gas meter. Therefore any reduction in collected $\mathrm{RGM}$ and $\mathrm{Hg}^{\mathrm{P}}$ through use of a pre-filter is greatly outweighed by the effects on the sample volume, and cannot be quantified. All data obtained using the revised sampler setup have been filtered to remove values where the apparent flow rate exceeded $0.1 \mathrm{~m}^{3}$ per day $\left(\sim 70 \mathrm{ml} \mathrm{min}^{-1}\right)$ and wherever the second cartridge showed a higher mercury level than the first, indicative of sample breakthrough.

Samples with potential contamination, e.g. from reported machinery use or grass cutting during the sampling period, or where the sampler was faulty, have also been excluded. Data points outside two standard deviations of the mean have also been excluded during analysis in order to remove outliers from the data sets. These may arise as artefacts of the sampling system, or may be real values where the sampler was not sampling 'background' air (i.e. local contamination), and have been excluded on the grounds that the network was established to quantify the regional patterns of mercury concentrations in rural areas of the UK, free from any occasional localised sources.

Interpolation of the data over the UK was carried out using the Ordinary Kriging method. This geo-statistical method assesses the statistical relationship 
between data points to create a prediction for the areas in between, giving a measure of the prediction accuracy. It uses the distance between data points as well as the distribution of points when 'weighting' them for interpolation. In comparison, inverse distance weighting (IDW) takes no account of distribution and has no measure for error in the interpolated results. Other advantages of the Kriging method as used here include: the assumption of an unknown mean value, the minimisation of variance, and removal of bias from the interpolated data. Here the spherical semivariogram model has been applied for the interpolation ${ }^{22}$.

\section{Continuous speciated atmospheric mercury monitoring at Auchencorth Moss}

Levels of atmospheric mercury were monitored between January 2005 and December 2008 at the Auchencorth Moss field site operated by $\mathrm{CEH}$ on behalf of DEFRA, located in Midlothian, about $20 \mathrm{~km}$ south-west of Edinburgh at approximately $55^{\circ} 45^{\prime} \mathrm{N}, 3^{\circ} 15^{\prime} \mathrm{W}$. This is a rural, sheep-grazed, upland peat site with a large, uniform fetch in a remote location, comprising assorted species of grass, heather and mosses. The surrounding land areas are also farmed for cattle and sheep, as

well as some wooded areas. The field site was originally established by $\mathrm{CEH}$ in 1995, and is now operated as a level III EMEP site, part of the Co-operative programme for monitoring and evaluation of long-range transmission of air pollutants in Europe, a high quality site measuring a wider range of atmospheric pollutants than at the more basic level I EMEP sites (see http://emep.int for further details).

\section{Mercury analyser}


Measurements of the three mercury species were made using the Tekran mercury speciation system, allowing measurement of gaseous elemental mercury $\left(\mathrm{Hg}^{0}\right)$, reactive gaseous mercury (RGM) and particulate mercury $\left(\mathrm{Hg}^{\mathrm{P}}\right) .{ }^{20}$ Sampling took place at a total flow rate of $10 \mathrm{~L} \mathrm{~min}^{-1}$ through an external inlet, $0.9 \mathrm{~m}$ off the ground. RGM and $\mathrm{Hg}^{\mathrm{P}}$ were removed from the sampled air stream before a flow of $0.9 \mathrm{~L} \mathrm{~min}^{-1}$ was removed by the $2537 \mathrm{~A}$ for analysis of $\mathrm{Hg}^{0}$. The speciation units were then sequentially desorbed during the analysis phase.

The 2537A analyser uses an automated dual channel amalgamation system with a resolution of 5 minutes, allowing continuous sampling of ambient air and the pre-concentration of mercury by adsorption onto one of the two gold cartridges, whilst the other cartridge is simultaneously desorbed and analysed ${ }^{2021}$.

Note that this is the same 2537A that was used for the network trap desorption and was taken offline every 2 weeks for several hours for trap analysis. It should also be noted that the RGM and $\mathrm{Hg}^{\mathrm{P}}$ units suffered from several extended periods of down time due to faults and repair.

\section{QA/QC}

Automatic calibrations of the 2537A occurred every 26 hours using the internal permeation source. Two point calibrations, a zero and a span, are completed separately for each cartridge with the permeation source giving $\sim 1 \mathrm{pg} \mathrm{s} \mathrm{s}^{-1} @ 50{ }^{\circ} \mathrm{C}$. This was supplemented by regular permeation source verification tests using the Tekran 2505 external calibration source. This process verifies the emission rate and calibration accuracy ${ }^{23}$. 
Sample line filters were changed monthly, zero air line filters annually. The RGM denuder was changed monthly and the particulate trap was changed quarterly. Both were regenerated as per Tekran guidance ${ }^{20}$. The detection limit of the 2537A as reported by Tekran is $<0.1 \mathrm{ng} \mathrm{m}^{-324}$.

Following sampling and analysis, erroneous data were removed (i.e. due to servicing or sample line verification) and any corrections applied (see below). The 5minute $\mathrm{Hg}^{0}$ data were then used to create hourly averages. The data for RGM and $\mathrm{Hg}^{\mathrm{P}}$ were summed to create hourly concentrations for the same hourly period as the $\mathrm{Hg}^{0}$ hourly average data. These hourly values were then used in the data analysis.

\section{Correction of continuous monitoring data}

Due to undiagnosed problems with the 2537A, a linear correction has been applied to the data from July 2006 - mid January 2009. This was due to contaminated internal cartridges in the $2537 \mathrm{~A}$, which led to increased baseline noise, under-reading for peak areas and the steady decline of recorded mercury levels, to significantly below the expected measurements ${ }^{25}$. By studying the raw data and the spread of recorded values on individual cartridges as well as a comparison of both cartridges, an approximate start to the period of sensitivity decrease was identified. An assumption was made that the trend for the period should be linear and constant, so an adjustment to the raw data was made to offset the decline to achieve a constant average. For this reason, the continuous speciation data presented here have not been used to assess the absolute current background levels or any temporal trend of mercury in the atmosphere, but only for an analysis of the peaks, troughs and sources of mercury levels at the Auchencorth site. It is for this same 
reason that we have not compared the data from the automated Tekran system and the manual trap systems at the Auchencorth site.

\section{Spatial and temporal patterns in the TGM network}

Table 1 shows the annual average TGM values from the 10 sampling sites for 2005 -2008. It can be seen that there is a large range of values, between 0.8 and 3 $\mathrm{ng} \mathrm{m}^{-3}$, but from the 4-year average values at each site there is a smaller range between $1.3 \pm 0.4 \mathrm{ng} \mathrm{m}^{-3}$ and $1.9 \pm 1.0 \mathrm{ng} \mathrm{m}^{-3}$.

Table 1 Sample site locations and averaged data for 2005 - 2008. [No annual average is available for the Heigham Holmes site in 2008 due to poor data capture.] See map in Fig. 2.

\begin{tabular}{|c|c|c|c|c|c|c|c|}
\hline Site & Description & Location & $\begin{array}{c}2005 \\
\text { Average }\end{array}$ & $\begin{array}{c}2006 \\
\text { Average }\end{array}$ & $\begin{array}{c}2007 \\
\text { Average }\end{array}$ & $\begin{array}{c}2008 \\
\text { Average }\end{array}$ & $\begin{array}{c}\text { 4-Year } \\
\text { Average }\end{array}$ \\
\hline Auchencorth & Open peatland & $55.793 \mathrm{~N},-3.243 \mathrm{E}$ & 1.46 & 1.54 & 1.46 & 1.23 & 1.44 \\
\hline Banchory & Woodland & $57.077 \mathrm{~N},-2.535 \mathrm{E}$ & 1.31 & 1.47 & 1.47 & 1.11 & 1.38 \\
\hline Beacon Hill & Farmland & $53.532 \mathrm{~N},-1.857 \mathrm{E}$ & 1.37 & 1.50 & 1.91 & 1.61 & 1.59 \\
\hline Cockley Beck & Upper grassland & $54.403 \mathrm{~N},-3.160 \mathrm{E}$ & 1.31 & 1.54 & 1.59 & 1.37 & 1.50 \\
\hline Cwmystwyth & Farmland & $52.352 \mathrm{~N},-3.805 \mathrm{E}$ & 1.51 & 3.00 & 1.97 & 1.34 & 1.90 \\
\hline Detling & Farmland & $51.307 \mathrm{~N}, 0.584 \mathrm{E}$ & 1.48 & 1.81 & 1.90 & 1.20 & 1.69 \\
\hline Heigham Holmes & Farmland & $52.727 \mathrm{~N}, 1.615 \mathrm{E}$ & 1.07 & 1.94 & 1.98 & - & 1.63 \\
\hline Monks Wood & Woodland & $52.404 \mathrm{~N},-0.234 \mathrm{E}$ & 1.53 & 1.73 & 1.60 & 1.41 & 1.64 \\
\hline Wytham Wood & Woodland & $51.770 \mathrm{~N},-1.330 \mathrm{E}$ & 1.39 & 1.56 & 1.65 & 0.84 & 1.47 \\
\hline Yarner Wood & Woodland & $50.596 \mathrm{~N},-3.711 \mathrm{E}$ & 1.18 & 1.51 & 1.42 & 1.03 & 1.31 \\
\hline
\end{tabular}

The levels recorded at these background sites are consistent with levels of mercury in the atmosphere from other similar studies, of between 1.5 and $1.7 \mathrm{ng} \mathrm{m}^{-3}$ (Table 2) ${ }^{14,21,26-27}$. This would be consistent with estimates of the background concentration in the northern hemisphere. The data presented here compare well with other sampling sites across Europe ${ }^{28}$, although showing generally slightly lower values at some sites. This may be due to the inclusion of coastal sites such as Mace Head, Ireland or Lista, Norway in other studies, which could have a significant 
portion of their measured mercury emitted from the Atlantic Ocean. Alternatively this could be a result of the difference between sampling heights, 1.5 metres used in this study compared to 5 metres at Mace Head (Table 2), with the possibility of increased surface removal of mercury leading to lower measured concentrations at the lower sampling height.

Table $2 \mathrm{Hg}^{0}$ and TGM (defined as $\mathrm{Hg}^{0}$ and RGM) concentrations, with sample inlet heights, from other atmospheric mercury monitoring studies at locations in the northern hemisphere

\begin{tabular}{|c|c|c|c|c|}
\hline Site & Monitoring Period & $\begin{array}{l}\text { Inlet Height } \\
\qquad(\mathrm{m})\end{array}$ & $\begin{array}{c}\mathrm{Hg}^{0} \\
\left(\mathrm{ng} \mathrm{m}^{-3}\right)\end{array}$ & $\begin{array}{c}\text { TGM } \\
\left(\mathrm{ng} \mathrm{m}^{-3}\right)\end{array}$ \\
\hline Harwell, UK ${ }^{14}$ & $1995-1996$ & - & - & 1.68 \\
\hline Lista, Norway ${ }^{28}$ & $1995-2002$ & - & - & 1.79 \\
\hline Mace Head, Ireland ${ }^{27}$ & $1995-2002$ & 5 & - & 1.75 \\
\hline Zingst, Germany ${ }^{29}$ & $1998-2004$ & 4 & - & 1.66 \\
\hline Salmon Falls Creek Reservoir, Idaho, USA ${ }^{26}$ & $2005-2006$ & 4 & $1.57 \pm 0.6$ & - \\
\hline St. Anicet, Quebec, Canada ${ }^{21}$ & 2005 & 3 & $1.65 \pm 0.42$ & - \\
\hline
\end{tabular}

The annual average data show no significant upward or downward temporal trend, indicating that TGM in the rural UK remained relatively constant during the period 2005-2008. Global emissions of mercury have been decreasing steadily over a number of years ${ }^{15,30}$, so it would be reasonable to expect a downward trend in UK TGM levels. However, with mercury being a global atmospheric pollutant, its background level in the atmosphere will be affected not only by regional sources, but also by global sources further afield. In the countries of the far-east, especially China, where industry is expanding rapidly and the use of coal is growing, atmospheric mercury emissions are set to rise, probably offsetting any major emission reduction in the Western economies such as the EU and the USA ${ }^{28,31}$. For the period 2005 - 2008, data for the EU as a whole shows that emission levels 
remained effectively unchanged following a year-on-year decrease between 1990 and $2004^{32}$.

\section{Cwmystwyth}

At the Cwmystwyth site in Wales, the data generally indicated atmospheric TGM levels higher than at most other sites, especially during 2006, when the average was almost double most other sites. Historically the Ystwyth valley has been mined extensively for lead, silver and other heavy metals with many spoil heaps left abandoned and exposed, remaining today uncovered by vegetation ${ }^{33}$. Work on lead contamination in the floodplains of the Ystwyth showed that where lead levels were raised due to mining pollution, so were the mercury levels, with uncontaminated river sediment having up to $0.09 \mu \mathrm{g}$ mercury per gram of soil and the Ystwyth having up to $1.8 \mu \mathrm{g} \mathrm{g}^{-134-35}$. This is more than double the average mercury content of soils found during the Environment Agency's UK Soil and Herbage Survey, which was $0.13 \mu \mathrm{g} \mathrm{g}^{-}$ ${ }^{136}$. It seems likely therefore that the samples from Cwmystwyth are unduly affected by the legacy of Wales' mining past, with greater local input of mercury to the atmosphere from the surrounding environment.

\section{Spatial patterns}

Data from each sampling site (except Cwmystwyth, to preclude skewing) were averaged for each of the years 2005 to 2008, as well as for the entire 4-year period. This 4-year average data set was then interpolated over the UK (Figure 2), so as to map the data, revealing a gradient in TGM levels across the UK, with higher levels being found at the sites in the south-east, decreasing at the sites further west and 
north. Trends like this have been seen before, with decreasing levels of atmospheric mercury as a function of distance from continental Europe ${ }^{28}$, suggesting that the heightened levels in the south-east are due to contaminated air masses moving in from the continent, where there are more industrial sources of mercury and therefore higher levels in the atmosphere. The interpolation in Figure 2a suggests that the west of Scotland would experience higher concentrations of atmospheric mercury than the east. The associated kriging error map in figure 2b, (which shows the uncertainty relating to the predicted concentrations of $2 \mathrm{a}$,) shows a higher error for this region and this is probably the result of the low density of sampling sites across Scotland for the interpolation. However, these higher concentrations might also reflect the generally larger concentrations observed at other west coast sites in Europe, as noted above for Mace Head and Lista. 
a.

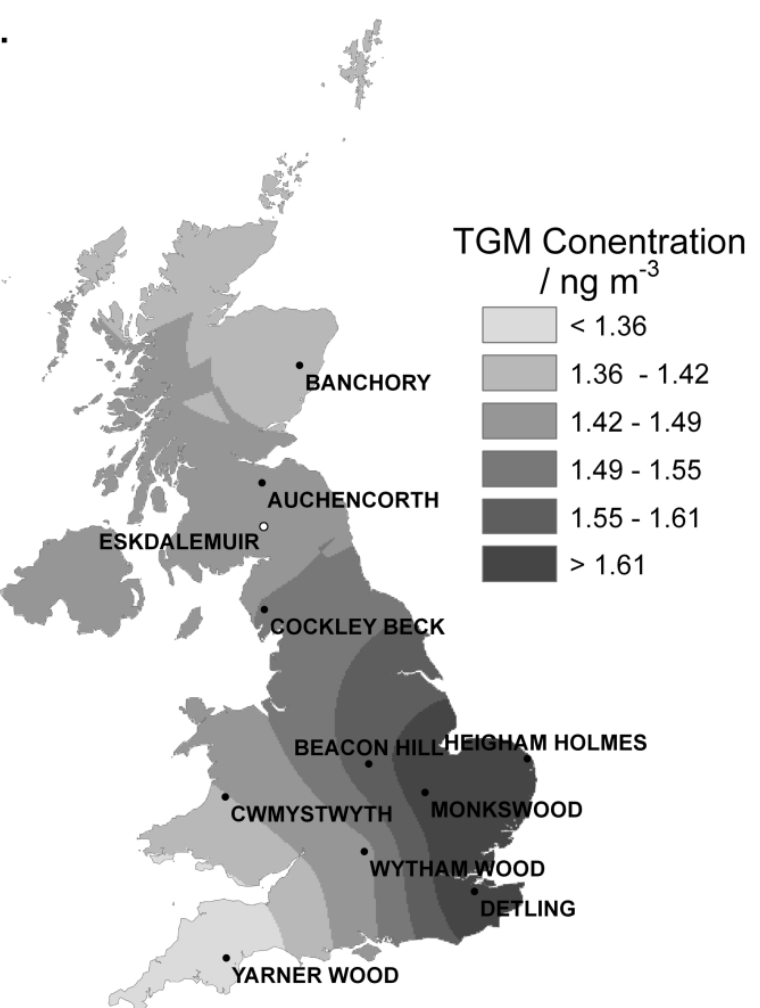

b.

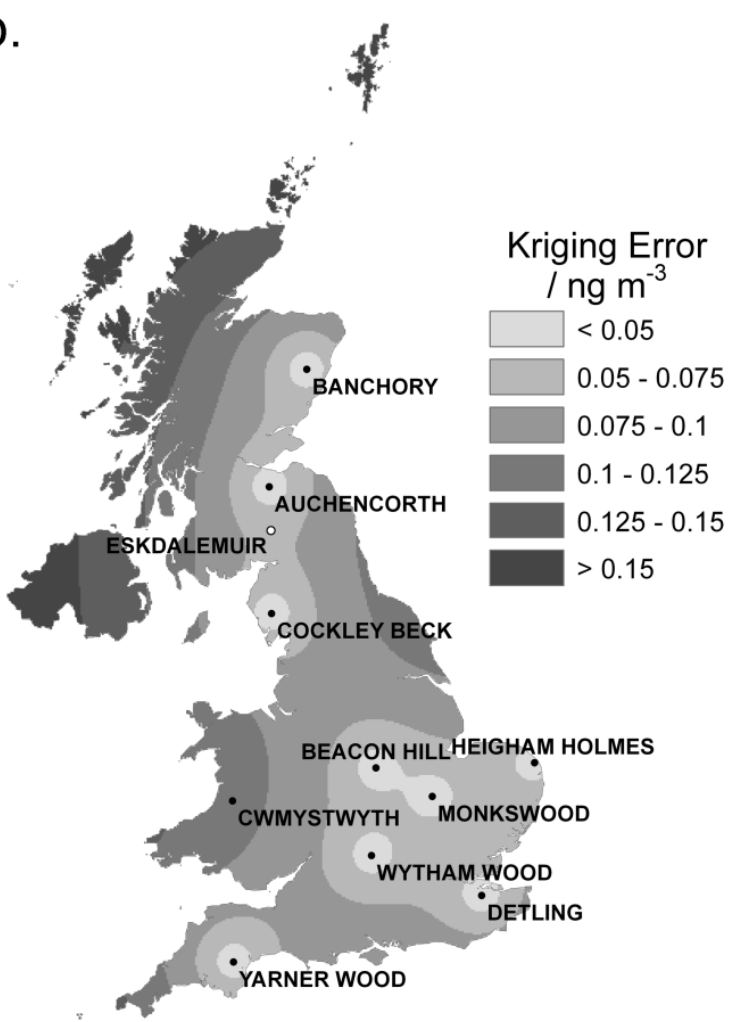

Fig. 2 a) Interpolated map of 4-year averaged data for all sampling sites, except Cwmystwyth, using Ordinary Kriging and (b) its associated error map

The National Physical Laboratory (NPL) operates a series of mercury samplers as part of the UK Heavy Metals Monitoring Network, which mainly comprises sites in urban locations, but also includes one rural site at Eskdalemuir in south-west Scotland. Using their data for the period $2005-2008^{37-40}$, the 4 -year average for the site was calculated to be $1.60 \pm 0.11 \mathrm{ng} \mathrm{m}^{-3}$. This is higher than would be expected according to the interpolated results, which predict a value of $1.46 \pm 0.07 \mathrm{ng} \mathrm{m}^{-3}$, but within the combined uncertainty. This suggests that the interpolation, whilst not perfect, is a good estimate of average TGM concentrations over the UK. Note also that the NPL data are not subject to rejection of outliers, so may include occasional monthly values influenced by local sources. Applying the 
same criteria to exclude outliers as used for the $\mathrm{CEH}$ dataset, the average value for Eskdalemuir would be $1.54 \pm 0.06 \mathrm{ng} \mathrm{m}^{-3}$, closer to the interpolated value.

\section{Seasonal patterns}

Average concentrations were calculated to look at seasonal trends within the data. Each site's data give the average concentration for an approximate 2-weekly period. Each day within that period was assigned this average concentration. An average concentration was then calculated for each month in the period $2005-2008$ across all sites (excluding Cwmystwyth) as divided by a south-west to north-east axis. The Auchencorth, Banchory, Cockley Beck and Yarner Wood sites fall into the north and west sector and the Beacon Hill, Detling, Heigham Holmes, Monkswood and Wytham Wood sites fall into the south and east sector. Figure 3 shows these two plots.

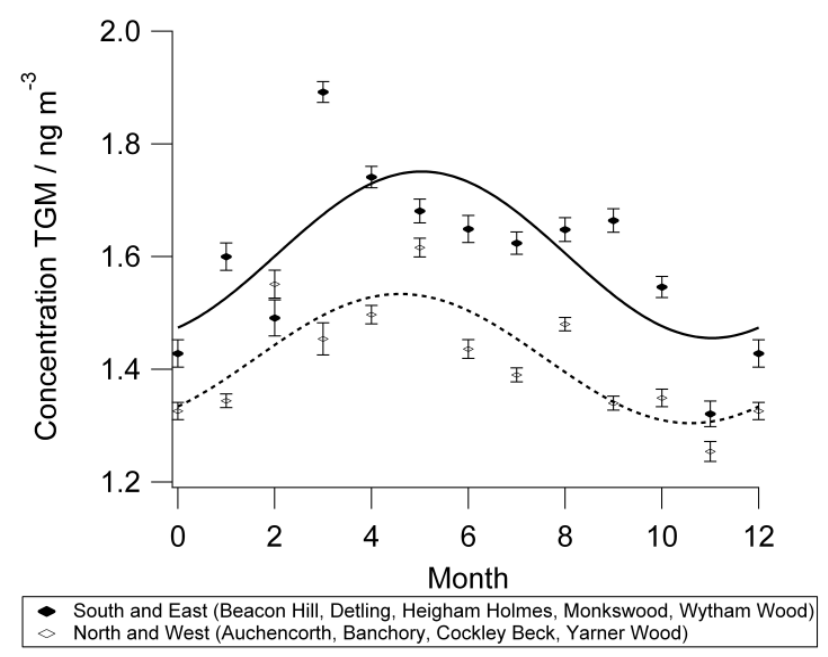

Fig. 3 Plot showing the difference in average monthly concentration and their standard errors between sites to the north and west compared to the south-east and the seasonal pattern (solid and dashed lines respectively) associated with them 
Figure 3 shows that the south and east sites have higher average monthly values than those in the north and west, where the difference between the two groups of data is statistically significant, (with $p<0.0003$ based on a paired t-test), giving weight to the idea of an atmospheric mercury concentration gradient across the UK. Both plots also seem to show a seasonal cycle of higher average concentrations during the spring and summer compared to the autumn and winter, but this trend fits the data from the north and west better $\left(R^{2}=0.64\right)$ than it does for the south and east $\left(R^{2}=0.49\right)$, which could be an indication of greater variability in atmospheric mercury concentrations in the south and east as opposed to a more stable background in the north and west. This seasonal trend is the opposite of that generally observed with atmospheric mercury. Other studies in other geographical regions have found there to be higher levels of mercury present during the winter months than the summer $27,41-43$. It is postulated that this is likely due to increased conversion of $\mathrm{Hg}^{0}$ to $\mathrm{RGM}$ and $\mathrm{Hg}^{\mathrm{P}}$ during the summer months, which are more easily removed through wet and dry deposition processes ${ }^{27}$. This seasonal cycle, with higher winter concentrations, can be seen in the UK wet deposition network data for mercury, which are co-located with the air samplers ${ }^{44}$. Higher winter levels may also be influenced by reduced air mixing heights and wind speeds ${ }^{16}$ or even an increase in coal combustion ${ }^{30}$.

The degree to which the plots in Figure 3 reflect one another would seem to indicate countrywide effects on TGM concentrations rather than local conditions such as reduced mixing in winter. This is probably another reflection of contaminated air masses moving across the UK, possibly an indication of influence by the North Atlantic Oscillation. During the summer, the Azores High has a greater influence over the UK weather, whereas during the winter, the Icelandic Low has the greater 
influence. Depending on the extent of the Azores High during the spring and summer, air over the UK would be more heavily influenced by continental Europe, bringing contaminated air to the UK and raising mercury concentrations. During the autumn and winter months the Icelandic Low would allow cleaner air masses to move in from the Atlantic Ocean, keeping the mercury levels lower.

\section{Variations in the continuous measurements at Auchencorth Moss}

The levels of $\mathrm{Hg}^{0}$ in the atmosphere as measured at the Auchencorth Moss field site are generally quite stable around an average value. However, there are peaks, troughs and extended periods with elevated concentrations in the data which are of interest. Here we have used the US National Oceanic and Atmospheric Administration (NOAA) Air Research Laboratory's HYbrid Single-Particle Lagrangian Integrated Trajectory (HYSPLIT) model ${ }^{45}$ to create back trajectories for air masses arriving at the Auchencorth field site so as to try to understand the origin of 'events' seen in the recorded mercury levels. The meteorological data set used to create the plots was the REANALYSIS (global, 1948-present). 
Table 3 Minima and maxima hourly average values of mercury species during trough and peak events respectively. (Where no $\mathrm{Hg}^{\mathrm{P}}$ or RGM data is given, it is due to analyser downtime.)

$\begin{array}{cccccc}\text { Event start date and time } & \begin{array}{c}\text { Event end date } \\ \text { and time }\end{array} & \begin{array}{c}\text { Duration } \\ \text { (Hours) }\end{array} & \begin{array}{cccc}\left(\mathrm{ng} \mathrm{m}^{-3}\right) & \left(\mathrm{pg} \mathrm{m}^{-3}\right) & \left(\mathrm{pg} \mathrm{m}^{-3}\right)\end{array}\end{array}$

$\underline{\text { Trough }}$

\begin{tabular}{|c|c|c|c|c|c|}
\hline 25/12/2005 06:15 & 26/12/2005 10:05 & 28 & 0.52 & - & - \\
\hline 29/12/2005 06:05 & 29/12/2005 10:05 & 4 & 0.46 & - & - \\
\hline 06/01/2006 11:25 & 06/01/2006 13:25 & 2 & 0.50 & - & - \\
\hline 29/01/2006 22:35 & 31/01/2006 09:15 & 35 & 0.32 & - & - \\
\hline 28/02/2006 19:50 & 05/03/2006 11:10 & 111 & 0.22 & - & - \\
\hline 29/05/2006 19:25 & 31/05/2006 10:50 & 37.5 & 0.55 & - & - \\
\hline 04/09/2006 19:55 & 05/09/2006 07:55 & 12 & 0.61 & - & - \\
\hline 29/09/2006 02:40 & 29/09/2006 04:40 & 2 & 0.61 & 0.0 & 0.10 \\
\hline \multicolumn{6}{|l|}{ Peak } \\
\hline 02/04/2005 16:55 & 03/04/2005 19:35 & 26.5 & 2.104 & 22.22 & 21.27 \\
\hline 18/06/2005 20:40 & 19/06/2005 14:40 & 17.5 & 2.15 & 5.83 & 47.84 \\
\hline 09/08/2005 14:20 & 09/08/2005 16:20 & 2 & 2.26 & 4.00 & 4.17 \\
\hline 31/08/2005 11:20 & 31/08/2005 15:20 & 4 & 2.09 & 16.16 & 76.03 \\
\hline 21/12/2005 04:20 & 24/12/2005 16:05 & 84 & 2.66 & - & - \\
\hline 18/01/2006 01:30 & 23/01/2006 00:20 & 119 & 3.25 & - & - \\
\hline 02/02/2006 04:35 & 02/02/2006 18:35 & 14 & 2.41 & - & - \\
\hline 23/02/2006 17:40 & 24/02/2006 13:40: & 20 & 2.24 & - & - \\
\hline 27/02/2006 02:45 & 27/02/2006 17:40 & 15 & 2.33 & - & - \\
\hline 23/03/2006 18:40 & 25/03/2006 13:40 & 43 & 2.11 & - & - \\
\hline 17/10/2006 07:50 & 17/10/2006 23:50 & 16 & 2.30 & 6.42 & 2.19 \\
\hline 13/02/20008 15:25 & 13/02/2008 19:25 & 4 & 2.87 & 0.02 & 0.0 \\
\hline
\end{tabular}

In the air-mass back-trajectories shown in Figure 4, each coloured line represents the trajectory of air arriving at the site, with each trajectory twenty-four hours apart. Each coloured marker on a trajectory shows the position of the air mass on its way to the site at 6-hour intervals. The height of the air mass above ground level can be ascertained from the chart beneath the map (Figures $4 a$ and $4 b$ ). The relative distances between coloured markers on the trajectories may be used to give 
an idea of the speed at which air masses have moved before reaching the Auchencorth site. The larger the distance between the points, the faster moving the air mass. For these data, peaks in $\mathrm{Hg}^{0}$ greater than 4 standard deviations from the mean and troughs more than 2 standard deviations from the mean were singled out for analysis. This identified 12 peaks or elevated mercury events and 8 troughs (Table 3). Two of these back trajectories are discussed below for illustration. The coloured points on the graph correspond to each of the trajectories and are plotted at the mean value for the entire $\mathrm{Hg}^{0}$ 2005-2008 dataset for comparison. 
a. NOAAHYSPLIT MODEL

a. Backward trajectories ending at 1200 UTC 26 Dec 05 CDC1 Meteorological Data
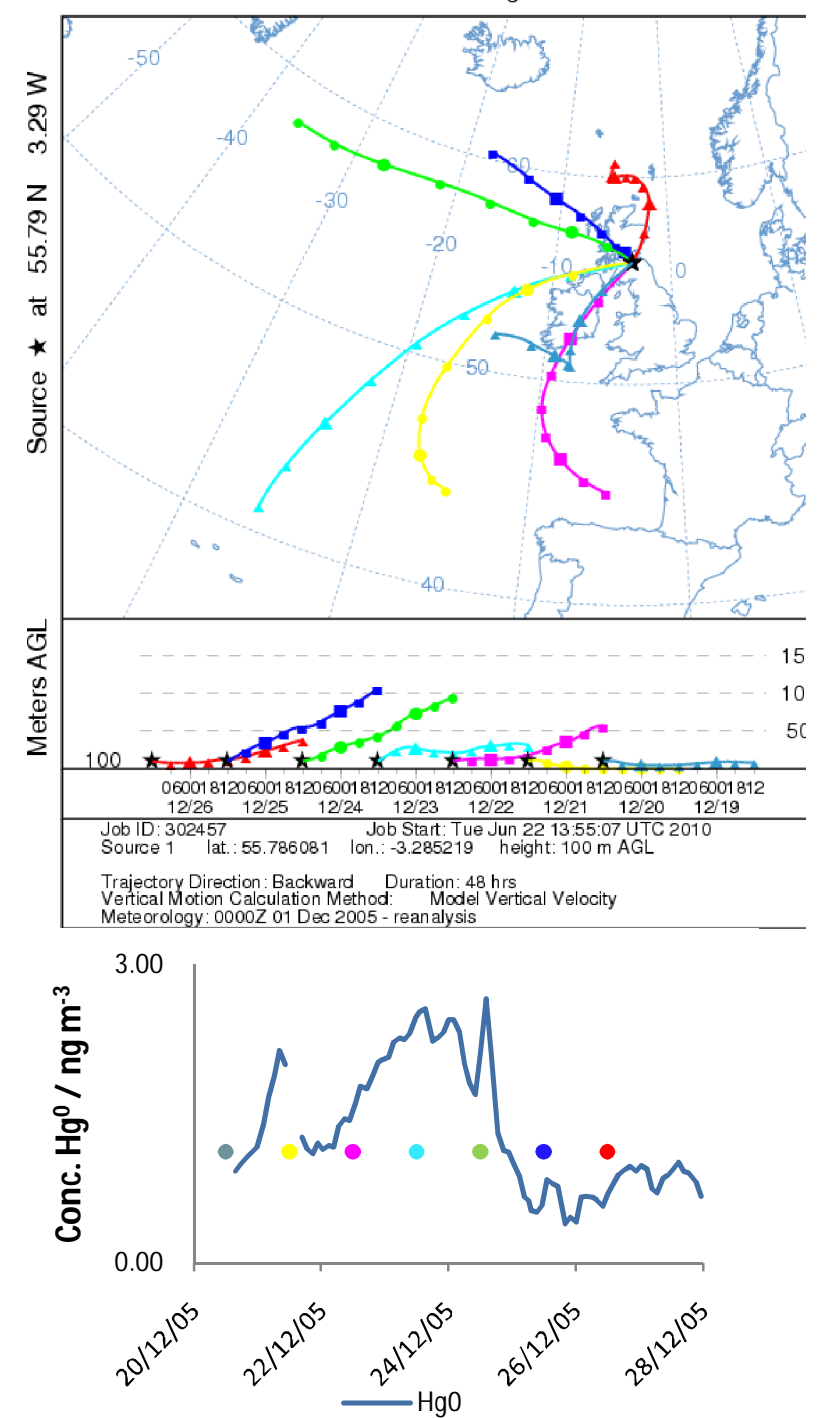

C.

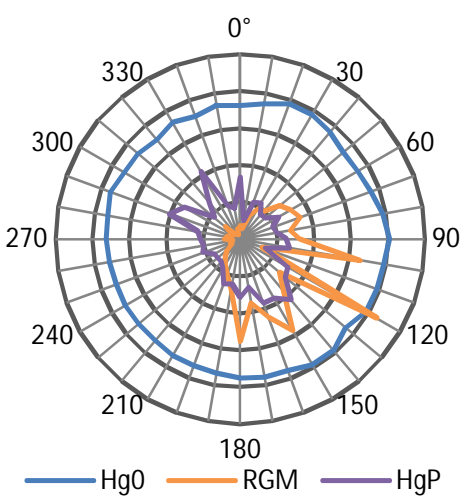

b. NOAA HYSPLIT MODEI

ectories ending at 0000 UTC 02 Sep 05 CDC1 Meteorological Data
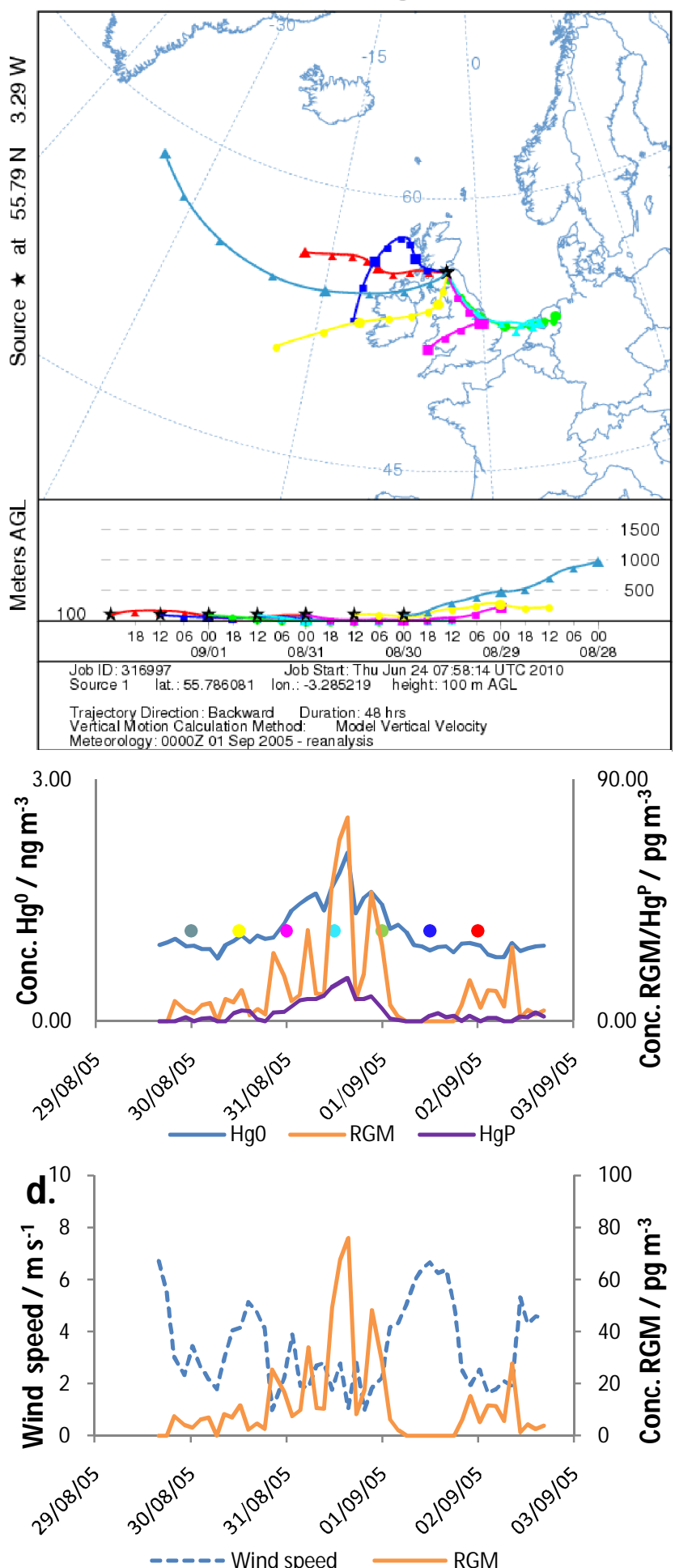

Fig. 4 Back-trajectories (24 hour intervals) and plots showing changes in the mercury species concentration at Auchencorth Moss, a) $20^{\text {th }}-28^{\text {th }}$ December 2005, b) $29^{\text {th }}$ August to $2^{\text {nd }}$ September 2005. c) Wind sector analysis showing directional dependence of average mercury species concentrations in $10^{\circ}$ sectors (Axis Max. $\mathrm{Hg}^{0}: 1.5 \mathrm{ng} \mathrm{m}^{-3}, \mathrm{Hg}^{\mathrm{P}}$ \& RGM: $6 \mathrm{pg} \mathrm{m}{ }^{-3}$ ). d) Plot showing the negative correlation between RGM and Windspeed, $29^{\text {th }}$ August to $2^{\text {nd }}$ September 2005 
Figure $4 \mathrm{a}$ shows the $\mathrm{Hg}^{0}$ data and associated back trajectories for the air masses arriving at the Auchencorth field site between the $20^{\text {th }}$ and $28^{\text {th }}$ December 2005 which gave rise to both a peak and a trough in the data. These back trajectories show that at the start of the period, low lying air is moving slowly from the Atlantic, over Ireland and up to Auchencorth (teal), followed by low lying air moving from the south in the Bay of Biscay, probably originating over the continent, which has the effect of gradually increasing the $\mathrm{Hg}^{0}$ levels observed (yellow \& fuchsia.) The direction of the air then veers around through the south-west (cyan) to the west (green), where the $\mathrm{Hg}^{0}$ level peaks sharply before dropping rapidly. This sharp peak coincides with the green trajectory air mass arriving at the site bringing free tropospheric air from higher altitudes. The sharpness of the peak at 10:00 on $24^{\text {th }}$ December probably indicates a local source to the west of the site in the industrialised central belt of Scotland. It did not correlate in time with a sharp peak in $\mathrm{SO}_{2}$ detected at 14:00 as wind veered further north bringing power station emissions across the site. Levels of $\mathrm{Hg}^{0}$ then decrease, probably due to the different source of air, and also the increase in origin height. This dip in $\mathrm{Hg}^{0}$ is then sustained (blue and red) whilst the wind direction prevails from the north.

Figure $4 \mathrm{~b}$ shows the speciated mercury data and associated back trajectories for the air masses arriving at the Auchencorth field site between the $30^{\text {th }}$ August and $2^{\text {nd }}$ September 2005, giving rise to peaks in all three mercury species. In these back trajectories, levels of the three species are low initially as faster, higher level air descends from the west over the Atlantic (teal). As a weather front moves in from the west, the air masses slow as they back around, arriving from the south-west and then the south-east, with air arriving from lower levels, bringing air from over the UK, but also from continental Europe, leading to a gradual increase in levels (yellow, 
pink, blue and green). The air masses then move to a westerly flow once the weather front has moved over the UK, coming from the south-west and then west (blue, then red), again bringing air from over the Atlantic, albeit this time from a lower height, reducing the levels back to those indicated on the plot before the peak in question. During this event the variation in $\mathrm{Hg}^{\mathrm{P}}$ concentration is relatively smooth and consistent with that of $\mathrm{Hg}^{0}$. For RGM, ground level wind speeds greater than 5 $\mathrm{ms}^{-1}$ at the site delivered little or none of the species, whilst wind speeds less than 5 $\mathrm{ms}^{-1}$ delivered higher levels (Figure 4d). It is these fluctuations in local wind speeds which appear to be responsible for the oscillations in RGM concentrations seen in Figure 4b, which could be indicative of a local unidentified RGM source.

The breakdown of back trajectories for all the identified periods of peaks and troughs in Table 3 reveal that peaks in mercury concentrations are associated with slower moving air masses (shorter plotted trajectories) in 8 of the 12 periods identified as 'peaks'. For example, in Fig. 4a the trajectory ending at midday on the $26^{\text {th }}$ December covers on average $360 \mathrm{~km}$ day $^{-1}$. However, 'troughs' in concentration are associated with faster moving masses (longer plotted trajectories) in 7 of the 8 periods identified. For example, in Fig. 4 a the trajectory ending at midday on the $23^{\text {rd }}$ December covers on average $1200 \mathrm{~km} \mathrm{day}^{-1}$. The height from which the air arrives at the site seems to play a smaller part, with 'troughs' generally originating from nearsurface (up to $500 \mathrm{~m}$ above ground level (AGL)) in 7 of 8 events, whereas 'peaks' may be seen from trajectories up to 1500 m AGL.

The more important factor for variations in the mercury level is the direction from which air masses arrive and what they have passed over. Peaks in mercury generally originate in air masses which arrive from $90^{\circ}(\mathrm{E})$ clockwise to $225^{\circ}(\mathrm{SW})$, 
i.e. in southerly and easterly flow (8 of 12 events), and troughs from $225^{\circ}$ (SW) clockwise to $90^{\circ}(\mathrm{E})$, i.e. in westerly and northerly flow (all 8 events). This trend can also been seen in Figure 4c; which shows wind sector analysis plots for averages of the three mercury species over the whole period 2005 - 2008. Elemental mercury is on average $4.2 \%$ higher when the prevailing wind is from the south-east than when from the north-west, but also has a peak in average values between $20-30^{\circ}$ from $\mathrm{N}$ which shows the likely influence of the city of Edinburgh and the coal-fired power station at Cockenzie $(28 \mathrm{~km})$. For RGM, distinctly higher average values are seen between $90^{\circ}(\mathrm{E})$ and $180^{\circ}(\mathrm{S})$, indicating a strong south-easterly influence, indeed the south-easterly average is $45 \%$ higher than north-westerly. $\mathrm{Hg}^{\mathrm{P}}$ also shows a south-easterly bias, but also has high average peaks at $290^{\circ}$ and $330^{\circ}$. These latter could be the influence of the Grangemouth petrochemical refinery (38 km) or Longannet coal-fired power station $(41 \mathrm{~km})$ to the north-west. This study has identified a limited number of 'events' for analysis; with a larger continuous dataset and comparison to tracers such as marine sodium and non-marine sulphate, nitrate etc. a better understanding of the effect of local and long range transport could be achieved.

\section{Conclusions}

The data presented here show no evidence of either an upward or downward trend in measured TGM levels in the UK over the period. The data do show a clear southeast to north-west gradient in TGM levels across the UK, probably predominantly from the influence of incoming air masses from continental Europe under highpressure easterly flow regimes. This would be consistent with other studies which 
have looked at sources of heavy metals contaminants in air using air mass back trajectories ${ }^{46}$. The levels in the south-east of the UK are closer to other observed levels concentrations of background mercury measured on the continent, with those further north in the UK less so. This could be an indication that the northern hemisphere background level of mercury is lower than previously thought, and that results from other studies may be more affected by regional emissions than expected. Alternatively, it may result from the lower sampling height $(1.5 \mathrm{~m})$ used in this study in comparison with some others. However, the large uncertainties associated with these regions (Figure $2 \mathrm{~b}$ ) show that more data in the north-western areas of the UK and from elsewhere across Europe would be needed to test these hypotheses.

\section{Acknowledgements}

The measurements reported here were made under contract to the UK Department of the Environment, Farming and Rural Affairs (CPEA32). We acknowledge with gratitude the local site operators without whom the network could not exist, and our colleagues in $\mathrm{CEH}$ who manage the project and maintain the sites.

\section{References}

1. R. Ferrara, B. Mazzolai, E. Lanzillotta, E. Nucaro and N. Pirrone, Science of the Total Environment, 2000, 259, 183 - 190.

2. M. S. Gustin, Applied Geochemistry, 2008, 23, 482-493.

3. W. H. Schroeder and J. Munthe, Atmospheric Environment, 1998, 32, 809822.

4. E. G. Pacyna, J. M. Pacyna and N. Pirrone, Atmospheric Environment, 2001, 35, 2987 - 2996. 
5. P. Pai, D. Niemi and B. Powers, Fuel Processing Technology, 2000, 65, 101115.

6. T. Bergan, L. Gallardo and H. Rodhe, Atmospheric Environment, 1999, 33, 1575-1585.

7. D. S. Lee, E. Nemitz, D. Fowler and R. D. Kingdon, Atmospheric Environment, 2001, 35, 5455-5466.

8. P. A. Ariya, A. Khalizov and A. Gidas, Journal of Physical Chemistry A, 2002, 106, 7310-7320.

9. S. E. Lindberg, S. Brooks, C.-J. Lin, K. J. Scott, M. S. Landis, R. K. Stevens, M. Goodsite and A. Richter, Environ. Sci. Technol., 2002, 36, 1245 - 1256.

10. L. Poissant, M. Pilote, X. Xu, H. Zhang and C. Beauvais, Journal of Geophysical Research, 2004, 109.

11. A. Steffen, W. Schroeder, R. Macdonald, L. Poissant and A. Konoplev, Science of the Total Environment, 2005, 342, 185-198.

12. C. Temme, P. Blanchard, A. Steffen, C. Banic, S. Beauchamp, L. Poissant, R. Tordon and B. Wiens, Atmos Environ, 2007, 41, 5423-5441.

13. P. A. Ariya, A. P. Dastoor, M. Amyot, W. H. Schroeder, L. Barrie, K. Anlauf, F. Raofie, A. Ryzhkov, D. Davignon, J. Lalonde and A. Steffen, Tellus, 2004, 56B, 397 - 403.

14. D. S. Lee, G. J. Dollard and S. Pepler, Atmospheric Environment, 1998, 32, 855-864.

15. P. Schuster, D. P. Krabbenhoft, D. L. Naftz, L. D. Cecil, M. L. Olson, J. F. Dewild, D. D. Susong, J. R. Green and M. L. Abbot, Environ. Sci. Technol., 2002, 36, $2303-2310$.

16. P. Blanchard, F. A. Froude, J. B. Martin, H. Dryfhout-Clark and J. T. Woods, Atmospheric Environment, 2002, 36, 3735-3743.

17. R. P. Mason, N. M. Lawson and G. R. Sheu, Atmospheric Environment, 2000, 34, 1691 - 1701.

18. M. Sakata and K. Marumoto, Atmospheric Environment, 2005, 39, 3139-3146.

19. P. Holmes, K. A. F. James and L. S. Levy, Science of the Total Environment, 2009, 408, 171-182.

20. M. S. Landis, R. K. Stevens, F. Schaedlich and E. M. Prestbo, Environ. Sci. Technol., 2002, 36, 3000 - 3009.

21. L. Poissant, M. Pilote, C. Beauvais, P. Constant and H. H. Zhang, Atmospheric Environment, 2005, 39, 1275-1287.

22. R. Webster and M. A. Oliver, Geostatistics for Environmental Scientists, John Wiley \& Sons Ltd, Chichester, 2001.

23. Tekran, Model 2537A Mercury Vapor Analyzer User Manual, 2.21 edn., Toronto, Canada, 1999.

24. Tekran, The Tekran Ambient Monitoring System: Continuous Ultra-Trace mercury Vapor Analysis, 2009.

25. P. C. Swartzendruber, D. A. Jaffe and B. Finley, Atmospheric Environment, 2009, 43, 3648-3651.

26. M. L. Abbott, C.-L. Lin, P. Martian and J. Einerson, Applied Geochemistry, 2008, 23, 438 - 453.

27. R. Ebinghaus, H. H. Kock, A. M. Coggins, T. G. Spain, S. G. Jennings and C. Temme, Atmospheric Environment, 2002, 36, 5267-5276.

28. I. Wängberg, J. Munthe, T. Berg, R. Ebinghaus, H. H. Kock, C. Temme, E. Bieber, T. G. Spain and A. Stolk, Atmospheric Environment, 2007, 41, 26122619. 
29. H. H. Kock, E. Bieber, R. Ebinghaus, T. G. Spain and B. Thees, Atmospheric Environment, 2005, 39, 7549 - 7556.

30. F. Slemr and H. E. Scheel, Atmospheric Environment, 1998, 32, 845 - 853.

31. N. Pirrone, S. Cinnirella, X. Feng, R. B. Finkelman, H. R. Friedli, J. Leaner, R. Mason, A. B. Mukherjee, G. B. Stracher, D. G. Streets and K. Telmer, Atmospheric Chemistry and Physics, 2010, 10, 5951-5964.

32. European Union emission inventory report $1990-2008$ under the UNECE Convention on Long-range Transboundary Air Pollution (LRTAP) 7/2010, European Environment Agency, Denmark, 2010.

33. K. C. Jones, P. J. Peterson and B. E. Davies, Minerals and the Environment, 1983, 5, 122-127.

34. B. E. Davies, Geoderma, 1976, 16, 183-192.

35. B. E. Davies, Hydrobiologia, 1987, 149, 213-220.

36. H. Morgan, R. D. Burca, I. Martin and J. Jeffries, Soil Guideline Values for mercury in soil SC050021/Mercury SGV, Environment Agency, Bristol, 2009.

37. R. J. C. Brown, D. Butterfield, S. L. Goddard, D. Muhunthan, A. S. Brown and M. Williams, Annual Report for 2008 on the UK Heavy Metals Monitoring Network, National Physical Laboratory, Teddington, 2009.

38. R. J. C. Brown, D. M. Butterfield, S. L. Goddard, D. Muhunthan, M. Williams and R. E. Yardley, Annual Report for 2007 on the UK Heavy Metals Monitoring Network, National Physical Laboratory, Teddington, 2008.

39. R. J. C. Brown, M. Williams, D. Butterfield, R. E. Yardley, D. Muhunthan and P. T. Woods, Annual Report for 2005 on the UK Heavy Metals Network, National Pysical Laboratory, Teddington, 2006.

40. R. J. C. Brown, M. Williams, D. M. Butterfield, R. E. Yardley, D. Muhunthan and S. L. Goddard, Annual Report for 2006 on the UK Heavy Metals Monitoring Network, National Pysical Laboratory, Teddington, 2007.

41. K. H. Kim, R. Ebinghaus, W. H. Schroeder, P. Blanchard, H. H. Kock, A. Steffen, F. A. Froude, M. Y. Kim, S. M. Hong and J. H. Kim, J. Atmos. Chem., 2005, 50, 1-24.

42. J. Stamenkovic, S. Lyman and M. S. Gustin, Atmospheric Environment, 2007, 41, 6662-6672.

43. R. L. N. Yatavelli, J. K. Fahrni, M. Kim, K. C. Crist, C. D. Vickers, S. E. Winter and D. P. Connell, Atmospheric Environment, 2006, 40, 6650-6665.

44. A. P. Rowland, A. J. Lawlor, H. J. Guyatt and R. A. Wadsworth, Journal of Environmental Monitoring, 2010, 12, 1747-1755.

45. R. R. Draxler and G. D. Rolph, HYSPLIT (HYbrid Single-Particle Lagrangian Inetgrated Trajectory) Model, http://ready.arl.noaa.gov/HYSPLIT.php, 2010.

46. M. L. I. Witt, N. Meheran, T. A. Mather, J. C. M. de Hoog and D. M. Pyle, Atmospheric Environment, 2010, 44, 1524-1538. 